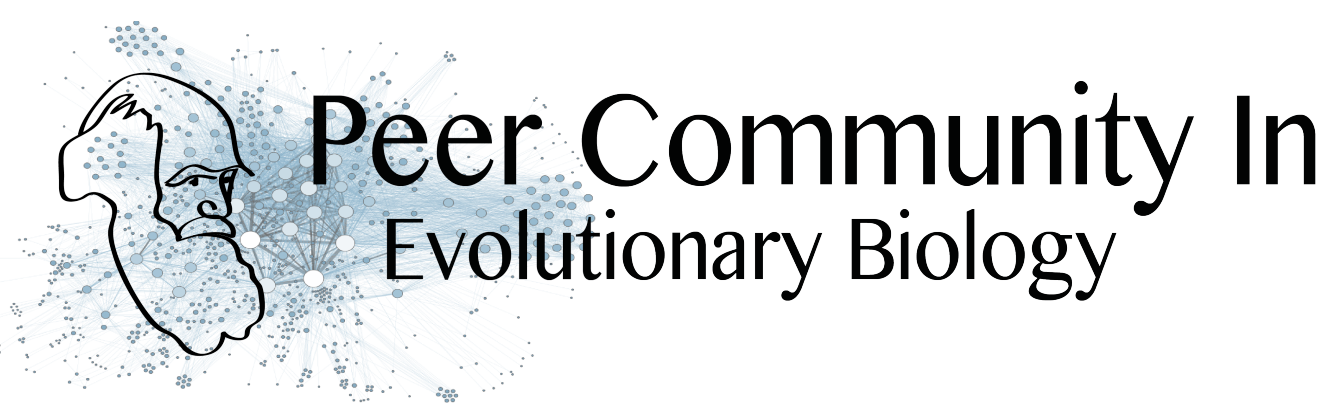

\%

\title{
Maternal effects in sex-ratio adjustment
}

\author{
Dries Bonte \\ Department of Biology, Ghent University -- Ghent, Belgium \\ Correspondence to Dries Bonte (Dries.Bonte@UGent.be) \\ doi: https://dx.doi.org/10.24072/pci.evolbiol.100051 \\ Published: 12th June 2018
}

Cite as: Bonte D. 2018. Maternal effects in sex-ratio adjustment. Peer Community In Evolutionary Biology, 100051 doi: https://dx.doi.org/10.24072/pci.evolbiol.100051

A recommendation - based on reviews by 2 anonymous referees - of
Duncan, A., Marinosci, C., Devaux, C., Lefèvre, S., Magalhães, S., Griffin, J., Valente, A., Ronce,
O., \& Olivieri, I. (2018). Transgenerational cues about local mate competition affect offspring sex
ratios in the spider mite Tetranychus urticae. bioRxiv, 240127 , ver. 3 peer reviewed and
recommended by PCI Evol Biol doi: https://dx.doi.org/10.1101/240127

\section{Open Access}

Optimal sex ratios have been topic of extensive studies so far. Fisherian 1:1 proportions of males and females are known to be optimal in most (diploid) organisms, but many deviation from this golden rule are observed. These deviation not only attract a lot of attention from evolutionary biologists but also from population ecologists as they eventually determine long-term population growth. Because sex ratios are tightly linked to fitness, they can be under strong selection or plastic in response to changing demographic conditions. Hamilton [1] pointed out that an equality of the sex ratio breaks down when there is local competition for mates. Competition for mates can be considered as a special case of local resource competition. In short, this theory predicts females to adjust their offspring sex ratio conditional on cues indicating the level of local mate competition that their sons will experience. When cues indicate high levels of LMC mothers should invest more resources in the production of daughters to maximise their fitness, while offspring sex ratios should be closer to 50:50 when cues indicate low levels of LMC.

In isolated populations, Macke et al. [2] found sex ratio to evolve fast in response to changes in population sex-structure in the spider mite Tetranychus urticae. Spider mites are becoming top-models in evolutionary biology because of their easy housekeeping, fast generation times and well-studied genome [3]. The species is known to respond fast to changes in relatedness and kin-structure by changing its mating strategy [4], but also dispersal [5]. Sex ratio adjustments are likely mediated by differential investments in egg size, with small eggs possibly 


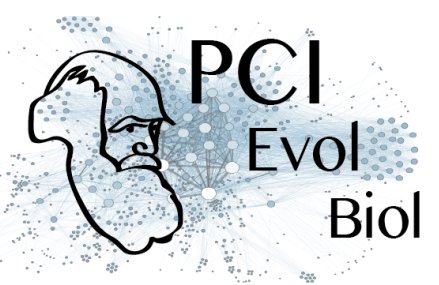

experiencing lower chances of fertilization, and thus to develop in haploid males [4].

Alison Duncan and colleagues [6] asked the question whether sex ratios change plastically in response to changes in the local population structure. They additionally questioned whether maternal effects could drive changes in sex-allocation of spider mite mothers. Indeed, theory predicts that if environmental changes are predictable across generations, intergenerational plasticity might be more adaptive than intragenerational plasticity [7]. Especially in spatially structured and highly dynamics populations, female spider mites may experience highly variable demographic conditions from one generation to another. During range expansions, spatial variation in local relatedness and inbreeding are documented to change and to impact eco-evolutionary trajectories as well (e.g. [8]).

Duncan et al. [6] specifically investigate whether the offspring sex ratio of $T$. urticae females changes in response to 1) the current number of females in the same patch, 2) the number of females in the patches of their mothers and 3) their relatedness to their mate. They surprisingly find the maternal environment to be more important than the actual experienced sex-ratio conditions. These insights thus show the maternal environment to be a reliable predictor of LMC experienced by grandchildren. Maternal effects have been found to impact many traits, but this study is the first to convincingly demonstrate maternal effects in sex allocation. It therefore provides an alternative explanation of the apparent fast evolved responses under constant demographic conditions [2], and adds evidence to the importance of non-genetic trait changes for adaptation towards changing demographic and environmental conditions.

\section{References}

[1] Hamilton, W. D. (1967). Extraordinary Sex Ratios. Science, 156(3774), 477-488. doi: https://dx.doi.org/10.1126/science.156.3774.477

[2] Macke, E., Magalhães, S., Bach, F., \& Olivieri, I. (2011). Experimental evolution of reduced sex ratio adjustment under local mate competition. Science, 334(6059), 1127-1129. doi: https://dx.doi.org/10.1126/science.1212177

[3] Grbić, M., Van Leeuwen, T., Clark, R. M., et al. (2011). The genome of Tetranychus urticae reveals herbivorous pest adaptations. Nature, 479(7374), 487-492. doi: https://dx.doi.org/10.1038/nature10640

[4] Macke, E., Magalhães, S., Bach, F., \& Olivieri, I. (2012). Sex-ratio adjustment in response to local mate competition is achieved through an alteration of egg size in a haplodiploid spider mite. Proceedings of the Royal Society B: Biological Sciences, 279(1747), 4634-4642. doi: https://dx.doi.org/10.1098/rspb.2012.1598

[5] Bitume, E. V., Bonte, D., Ronce, O., Bach, F., Flaven, E., Olivieri, I., \& Nieberding, C. M. (2013). Density and genetic relatedness increase dispersal distance in a subsocial organism. Ecology Letters, 16(4), 430-437. doi: https://dx.doi.org/10.1111/ele.12057

[6] Duncan, A., Marinosci, C., Devaux, C., Lefèvre, S.,Magalhães, S., Griffin, J., Valente, A., Ronce, O., Isabelle Olivieri Olivieri, I. (2018). Transgenerational cues about local mate competition affect offspring sex ratios in the spider mite Tetranychus urticae. BioRxiv, 240127, ver. 3. doi: https://dx.doi.org/10.1101/240127

[7] Petegem, K. V., Moerman, F., Dahirel, M., Fronhofer, E. A., Vandegehuchte, M. L., Leeuwen, T. V., Wybouw, N., Stoks, R., Bonte, D. (2018). Kin competition accelerates experimental range expansion in an arthropod herbivore. Ecology Letters, 21(2), 225-234. doi: https://dx.doi.org/10.1111/ele.12887

[8] Marshall, D. J., \& Uller, T. (2007). When is a maternal effect adaptive? Oikos, 116(12), 1957-1963. doi: https://dx.doi.org/10.1111/j.2007.0030-1299.16203.x

\section{Appendix}

Reviews by 2 anonymous referees: https://dx.doi.org/10.24072/pci.evolbiol.100051 